\title{
PENGGUNAAN SITUS LIVEWORKSHEETS UNTUK MENGEMBANGKAN LKPD INTERAKTIF DI SEKOLAH DASAR
}

\author{
Asri Fauzi ${ }^{1}$, Aisa Nikmah Rahmatih ${ }^{2 *}$, Dyah Indraswati ${ }^{3}$, Muhammad Sobri $^{4}$ \\ 1,2,3,4Universitas Mataram, Kota Mataram, Indonesia \\ *Penulis Koresponsensi, email: aisanikmahrahma07@unram.ac.id
}

Received:07/10/2020

Revised:16/10/2021

Accepted:18/10/2021

\begin{abstract}
Interactive student worksheets are a very important part of learning media to support the learning process to achieve the expected goals. The use of the liveworksheets site is one way to develop interactive worksheets so that online learning can run well. The purpose of this community service is to provide knowledge to teachers to take advantage of the free liveworksheets site to develop interactive worksheets so that the obstacles to teaching and learning activities during the Covid-19 pandemic can be overcome. The method of implementing this service begins with observations to partner schools before the implementation of training activities to discuss the time and need for facilities and infrastructure. Then during the training, the activity begins with the provision of material related to interactive student worksheets and how to create interactive student worksheets using the live worksheet site. Furthermore, assistance is provided during practice for teachers or training participants. The results of this service can be said to be successful, as seen from the enthusiasm of the teacher listening to the material and the practice of making interactive worksheets questions. The types of questions that were successfully practiced by the participants were the types of multiple-choice questions, short entries, descriptions, join arrows, dropdowns, drag and drop, checkboxes, word search, and listening and speaking questions. Therefore, with the increasing ability of teachers to create interactive worksheets, it is hoped that teachers can develop more perfect interactive worksheets that are made according to the needs of students. In addition, the knowledge that has been obtained from this training is expected for teachers to share their knowledge and knowledge with other teachers.
\end{abstract}

Keywords: liveworksheets, interactive student worksheets

Abstrak. Lembar kerjas peserta didik (LKPD) interaktif merupakan bagian media pembelajaran yang sangat penting guna mendukung proses pembelajaran untuk mencapai tujuan yang diharapkan. Pemanfaatan situs liveworksheets ini salah satu cara untuk mengembangkan LKPD interaktif sehingga pembelajaran daring bisa berjalan dengan baik. Tujuan pengabdian masyarakat ini yaitu untuk memberikan pengetahuan kepada guru untuk memanfaatkan situs gratis liveworksheets untuk mengembangkan LKPD interaktif sehingga kendala kegiatan belajar mengajar selama pandemic Covid-19 dapat teratasi. Metode pelaksanaan pengabdian ini diawali dari observasi ke sekolah mitra sebelum pelaksanaan kegiatan pelatihan untuk mendiskusikan waktu dan kebutuhan sarana dan prasarana. Kemudian pada saat pelatihan, kegiatan diawali dengan pemberian materi terkait LKPD interaktif dan bagaimana cara membuat LKPD interaktif menggunakan situs liveworksheet. Selanjutnya dilakukan pendampingan pada saat peraktik bagi guru atau peserta pelatihan. Hasil dari pengabdian ini dapat dikatakan berhasil dilihat dari antusias guru mendengarkan materi dan praktik membuat soal LKPD interaktif. Jenis soal yang berhasil dipraktikkan oleh peserta yaitu jenis soal pilihan ganda, isian singkat, uraian, join arrow, drop down, drag and drop, check box, word search, dan soal listening and speaking. Oleh karena itu dengan bertambahnya kemampuan guru untuk membuat LKPD interaktif diharapkan guru dapat mengembangkan lebih sempurna lagi LKPD interaktif yang dibuat sesuai dengan kebutuhan siswa. Selain itu juga, ilmu yang sudah didapatkan dari pelatihan ini, diharapkan bagi guru membagi pengetahuan dan ilmunya kepada guru-guru lain.

Kata Kunci: liveworksheets, LKPD Interaktif

How to Cite: Fauzi, A., Rahmatih, A. N., Indraswati, D., \& Sobri, M. (2021). Penggunaan Situs Liveworksheets untuk Mengembangkan LKPD Interaktıf di Sekolah Dasar. Mitra Mahajana: Jurnal Pengabdian Masyarakat, 2(3) 232-240. doi: https://doi.org/10.37478/mahajana.v2i3.1277

\section{PENDAHULUAN}

Pandemi Covid-19 yang terjadi di seluruh negara, khususnya di Indonesia mengubah proses pembelajaran yang biasanya dengan sistem luring menjadi sistem daring. Kebijakan ini diambil oleh pemerintah guna memutus rantai penularan Covid-19 demi kesehatan dan keselamatan masyarakat. Kebijakan ini tentu memberikan dampak yang luar biasa bagi Pendidikan di Indonesia. Pendidikan di Indonesia harus dipaksakan menggunakan 
pembelajaran secara daring tanpa adanya persiapan yang matang bagi guru dan peserta didik. Pendidik harus bekerja keras dalam menyusun ulang rencana dan strategi pembelajaran dari tatap muka menjadi daring (Rhosyida et al., 2021). Tanpa persiapan dan fasilitas yang memadai serta kompetensi yang cukup bagi masyarakat maka proses belajar mengajar secara daring akan sulit terlaksana dengan maksimal (Khikmiyah, 2021) (Ratnawati, 2021).

Pembelajaran daring merupakan salah satu metode pembelajaran yang harus dilakukan dalam proses belajar mengajar selama pandemi. Metode pembelajaran ini menggabungkan teknologi elektronika dan internet (Sao et al., 2021) (Nissa et al., 2021). Tanpa adanya internet maka pembelajaran daring tidak bisa dilaksanakan. Selain internet, banyak hal yang harus dipersiapkan oleh pendidik untuk menunjang dan memfasilitasi pembelajaran daring seperti materi, media, dan platform pembelajaran daring yang mudah digunakan oleh guru (Andriyani et al., 2020). Pembelajaran yang dilaksanakan secara daring tentunya menuntut guru untuk dapat merancang materi ajar digital. Menurut Alenezi (2020) materi ajar digital adalah seperangkat materi atau fitur yang dapat diakses melalui alat digital atau internet. Selain merancang materi ajar, tentu guru juga harus menyiapkan media pembelajaran untuk mendukung pencapaian tujuan pembelajaran.

Media pembelajaran merupakan alat bantu yang dapat dijadikan sebagai penyalur pesan dengan maksud untuk mencapai tujuan pengajaran (Lathifah et al., 2021). Sedangkan Muhson (2010) mengatakan bahwa media merupakan wadah dari pesan yang oleh sumber atau penyalurnya ingin diteruskan kepada penerima pesan. Media pembelajaran yang digunakan pada pembelajaran tematik harus memenuhi kriteria media yang baik agar dapat membantu keberhasilan pembelajaran secara maksimal (Arifin \& Aprisal, 2020) (Ermiana et al., 2020). Dalam hal ini yang menjadi penerima pesan adalah peserta didik yang menggunakan media yang sudah disiapkan oleh guru. Salah satu media pembelajaran yang dapat mendukung pembelajaran adalah Lembar Kerja Peserta Didik (LKPD).

Berdasarkan Depdiknas, LKPD merupakan lembaran berisi tugas yang harus dikerjakan oleh peserta didik, berupa petunjuk atau langkah menyelesaikan tugas dengan jelas (Widiyani \& Pramudiani, 2021). LKPD yang disusun berdasarkan kebutuhan peserta didik sangat penting untuk mempermudah kegitan pembelajaran agar efektif. Hal ini sejalan dengan yang dikatakan oleh Muskita et al. (2020) bahwa LKPD membantu mempermudah dalam kegiatan pembelajaran sehingga akan terbentuk interaksi yang efektif antara peserta didik dengan guru. Adanya interaksi tersebut maka dapat meningkatkan aktifitas peserta didik dalam peningkatan hasil belajar.

Namun, pada saat ini LKPD manual tidak bisa bekerja secara efektif dikarenakan pembelajaran dilakukan secara daring atau pembelajaran jarak jauh. Hal itu menjadi kendala bagi guru untuk memberikan media yang efektif untuk siswanya. Dengan adanya kendala seperti itu maka LKPD tersebut dibuat menjadi LKPD interaktif yang bisa di akses oleh peserta didik melalui internet. Guru hanya menyebarkan link LKPD interaktif yang sudah disusun kemudian dikerjakan secara online. Pembelajaran yang dilakukan menggunakan LKPD interaktif akan membuat suasana belajar lebih menyenangkan dan tidak merasa bosan (Ryabchikova et al., 2020).

Salah satu situs online gratis yang digunakan untuk membuat atau menyusun LKPD interaktif adalah Liveworksheets. Situs ini bisa diakses di www.liveworksheets.com secara gratis, namun pengguna harus registrasi untuk memperoleh sebuah akun. Jenis soal yang bisa dibuat di situs ini sangat beragam. Guru bisa memilih tipe soal drop-down (letakkan- turun), multiple choice (pilihan ganda), check boxes (mencentang), joint with arrow (menghubungkan), dragdrop (tarik dan letakkan) maupun listening-speaking (Hazlita, 2021). Guru juga bisa menggunakan soal yang telah dibuat pengguna lainnya dengan menyalin link soal tersebut dan membagikannya ke grup WA peserta didik. Kelebihan lain dari situs ini adalah setelah selesai mengerjakan evaluasi, system otomatis akan memberikan skor pada lembar kerja yang dikerjakan peserta didik.

Liveworksheets adalah platform dalam bentuk situs web yang menyediakan layanan kepada pendidik untuk dapat menggunakan E-LKPD yang tersedia dan membuat E-LKPD sendiri menjadi interaktif secara online. LKPD interaktif berbasis liveworksheets ini dapat dapat 
memberikan variasi belajar kepada peserta didik agar pembelajaran tidak membosankan. Disamping itu juga, LKPD interaktif ini mendorong peserta didik untuk aktif dalam pembelajaran dan memberikan kemudahan dalam belajar yang dilaksanakan secara daring (Prastika \& Masniladevi, 2021). Berdasarkan pemaparan diatas, maka tim pengabdian tertarik membuat kegiatan yaitu penggunaan situs liveworksheets untuk mengembangkan LKPD interaktif di sekolah dasar. Harapan dari kegiatan ini adalah supaya guru-guru disekolah dasar mempunyai pengalaman dan pengetahuan untuk membantu proses pembelajaran secara daring dengan membuat LKPD interaktif sesuai dengan kebutuhan siswa.

\section{METODE PELAKSANAAN}

Pada pelaksanaan pengabdian masyarakat ini, tim pengabdian terlebih dahulu berdiskusi terkait teknis pelaksanaan sebelum kegiatan inti di sekolah. Sasaran dari pengabdian masyarakat ini adalah guru sekolah dasar yang ada di kota Mataram. Metode pelaksanaan dalam program pengabdian masyarakat ini dapat menambah keterampilan guru untuk mengolah dan merancang LKPD interaktif yang dapat diakses oleh siswa secara online sehingga dapat menjadi solusi bagi guru pada pembelajaran. Lokasi pengabdian ini yaitu di SDN 12 Ampenan. Berikut ada peta lokasi pengabdian kepada masyarakat.

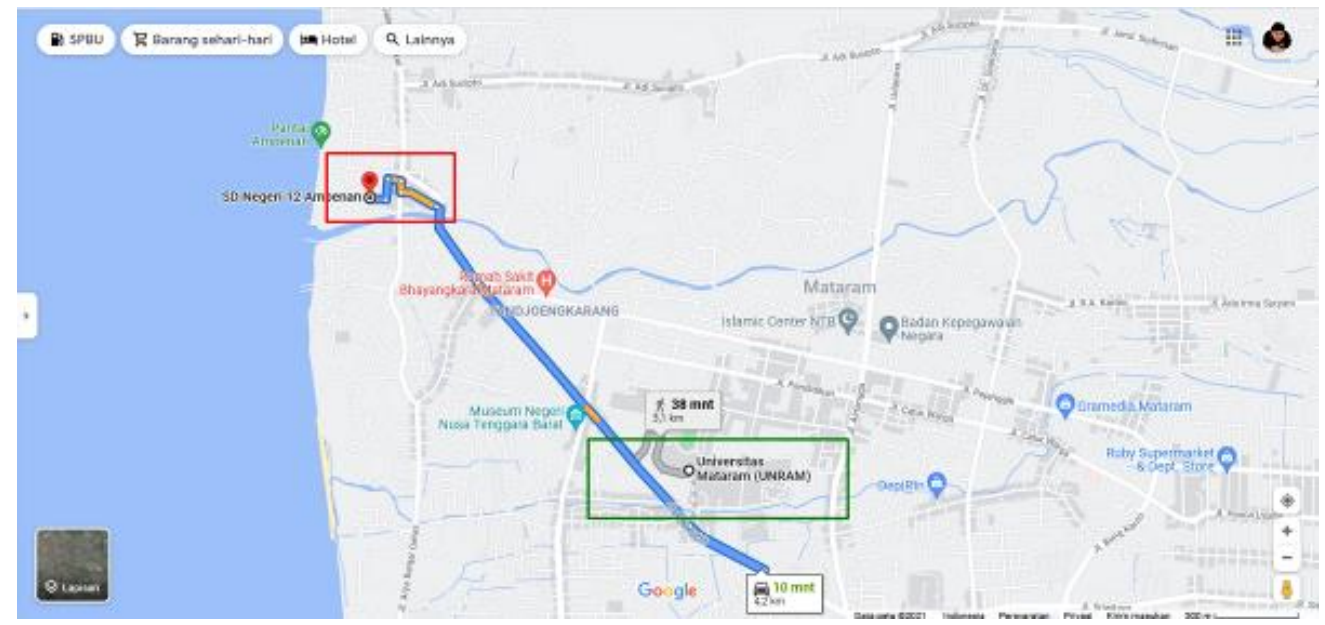

Gambar 1. Peta Lokasi Pengabdian Masyarakat

Berdasarkan peta lokasi pengabdian yang ditunjukan pada gambar 1, jarak antara kampus Universitas Mataram dengan lokasi pengabdian berjarak 3,1 km dengan waktu tempuh sekitar 10-20 menit menggunakan kendaraan. Lokasi SDN 12 Ampenan ini dipilih sebagai tempat pengabdian dikarenakan sekolah tersebut merupakan salah satu mitra FKIP Universitas Mataram khususnya prodi PGSD.

Metode pelaksanaan program PKM ini meliputi beberapa hal yaitu: pelaksanaan kegiatan ini diawali dengan melakukan observasi ke sekolah untuk bertemu kepala sekolah dan guru. Pada kegiatan observasi ini, tim pengabdian dan pihak sekolah berdiskusi tentang waktu pelaksanaan, tempat pelaksanaan, sarana dan prasarana yang harus disiapkan oleh mitra. Setelaha selesai observasi, tim pengabdian menyusun materi yang akan disampaikan. Materi yang disampaikan oleh tim pengabdian mengenai pengenalan LKPD interaktif yang diintegrasikan pada kearifan lokal sekitar, dan cara membuat LKPD interaktif yang baik. Materi tersebut disampaikan ketika pelatihan berlangsung. Kemudian setelah pelatihan dilanjutkan dengan proses pendampingan kepada guru-guru yang sedang melakukan praktik membuat LKPD interaktif menggunakan situs Liveworksheets.

Pada pengabdian ini, jenis soal yang dilatihkan atau dipraktikkan untuk dibuat oleh guru pada LKPD interaktifnya yaitu jenis soal pilihan ganda, isian singkat, uraian, join arrow, drop down, drag and drop, check box, word search, dan soal listening and speaking. Kemudian Bahasa yang digunakan dalam kegiatan pengabdian ini menggunakan Bahasa Indonesia. Sedangkan alat evaluasi untuk mengetahui pemahaman guru dan keberlanjutan pengabdian ini 
yaitu guru membuat LKPD interaktif secara mandiri ataupun berkelompok kemudian hasilnya diberikan kepada tim pengabdian masyarakat.

\section{HASIL DAN PEMBAHASAN}

Pengabdian kepada masyarakat merupakan kegiatan yang harus dilakukan oleh seorang dosen setiap tahunnya. Pengabdian ini dilakukan sebagai bentuk Tridharma Perguruan Tinggi guna memenuhi kewajiban seorang dosen untuk mengamalkan pengalaman, pengetahuan kepada masyarakat. Pada pengabdian ini mengangkat tema tentang penggunaan situs liveworksheets untuk mengembangakan LKPD interaktif di sekolah dasar.

Kegiatan pengabdian ini dilaksanakan pada tanggal 4 september 2021 yang diikuti oleh 10 orang guru SDN 12 Ampenan. Pengabdian yang dilaksanakan dapat dikatakan berjalan dengan lancar yang ditandai dengan antusias guru mengikuti pelatihan. Pelatihan ini diawali dengan memberikan materi kepada guru yang disampaikan oleh tim pengabdian secara bergiliran. Kemudian setelah selesai pemberian materi, maka dilanjutkan pada sesi pendampingan kepada guru-guru yang memperaktikkan bagaimana membuat LKPD interaktif dari situs www.liveworksheets.com. Namun sebelum membuat LKPD interaktif, tim pengabdian memandu guru-guru terlebih dahulu untuk melakukan registrasi dan menyiapkan bahan atau soal yang akan dijadikan LKPD interaktif sehingga siswa bisa mengakses secara online baik menggunakan device computer, laptop, maupun smartphone yang dimiliki siswa.

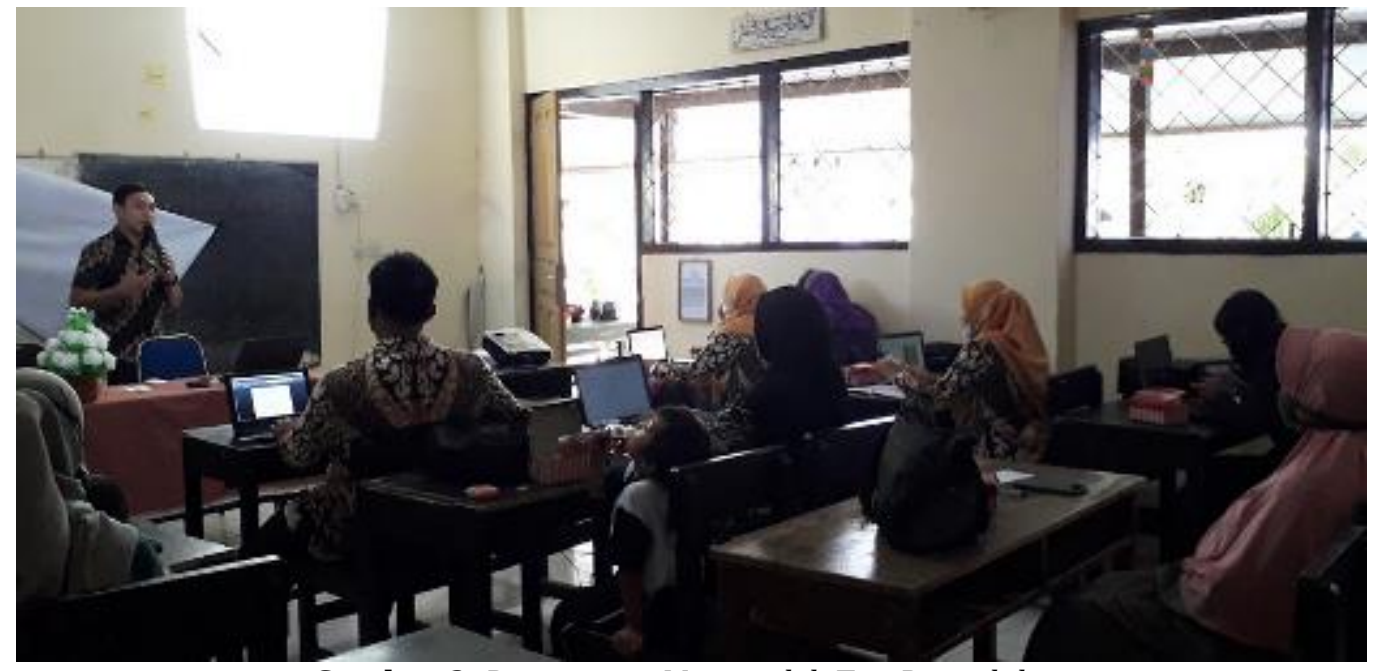

Gambar 2. Pemaparan Materi oleh Tim Pengabdian

Gambar 2 merupakan salah satu dokumentasi kegiatan pengabdian pada sesi pemaparan materi oleh tim pengabdian tentang tata cara membuat LKPD interaktif menggunakan situs liveworksheets. Pada sesi ini, guru atau peserta pelatihan diberikan kesempatan menceritakan pengalamannya ketika proses pembelajaran daring dan metode pembelajaran yang digunakan selama ini. Dari pemaparan yang disampaikan oleh guru disimpulkan bahwa dalam pembelajaran daring, rata-rata guru menggunakan platform Watshapp. Alasannya adalah karena WA ini lebih simple dan tidak menyulitkan guru maupun siswa dalam menggunakannya. Kemudian ketika melakukan penilaian guru-guru mengirimkan soal melalui Watshapp Group (WAG) dan dikumpulkan kembali melalui WAG. Namun pembelajaran daring yang hanya menggunakan platform WA tidak begitu efektif karena akan menghabiskan kuota yang cukup banyak untuk mengirimkan file, kemudian storage/ruang penyimpanan yang terbatas.

Untuk mengatasi keterbatasan yang dialami oleh guru, maka tim pengabdian memberikan solusi menggabungkan platform WA dan liveworksheets. LKPD interaktif yang dibuat dari liveworksheet ini memiliki keistimewaan dan menguntungkan bagi guru diantaranya yaitu guru hanya memberikan link LKPD yang sudah disusun kemudian link tersebut bisa diakses oleh siswa. Liveworksheets ini memudahkan penggunanya baik guru maupun siswa dalam mengerjakan secara langsung dan langsung mendapatkan feedback atau muncul nilai dari hasil 
kerja siswa (Prastika \& Masniladevi, 2021). Kelebihan lainnya bagi guru yaitu menghemat waktu, menghemat kertas, sedangkan bagi siswa yaitu interaktif dan memotivasi (Amalia \& Lestyanto, 2021).

Beberapa jenis soal yang diuji cobakan pada pengabdian ini yaitu jenis soal pilihan ganda, isian singkat, uraian, join arrow, drop down, drag and drop, check box, word search, dan soal listening and speaking. Sebelum kita peraktik membuat semua jenis soal tim pengabdian terlebih dahulu menjelaskan bagaimana script atau perintah bahasa di dalam liveworksheets itu supaya soal yang kita buat bisa berfungsi dengan baik. Adapun script semua jenis soal yang diperaktikan sebagai berikut:

Tabel 1. Script Jenis Soal Pada Liveworksheets

\begin{tabular}{cll}
\hline No & \multicolumn{1}{c}{ Jenis Soal } & \multicolumn{1}{c}{ Script } \\
\hline 1 & Pilihan Ganda & $\begin{array}{l}\text { Jawaban benar ketik select:yes } \\
\text { Jawaban salah ketik select:no }\end{array}$ \\
\hline 2 & Isian singkat & Langsung diketik kunci jawabannya \\
\hline 3 & Join arrow & $\begin{array}{l}\text { Join:1 pasangkan dengan } \text { join:1 } \\
\text { Join:2 pasangkan dengan } \text { join:2 }\end{array}$ \\
\hline 4 & Drop down & $\begin{array}{l}\text { choose:*jawaban benar/ jawaban salah/ } \\
\text { jawaban } \text { salah }\end{array}$ \\
\hline 5 & Drag and drop & $\begin{array}{l}\text { drag:1 pasangkan dengan } \text { drop:1 } \\
\text { drag:2 pasangkan dengan } \text { drop:2 } \\
\text { dst. }\end{array}$ \\
\hline 6 & Check Box & $\begin{array}{l}\text { Jawaban benar ketik tick:yes } \\
\text { Jawaban salah ketik tick:no }\end{array}$ \\
\hline 7 & Word search & $\begin{array}{l}\text { Ketik } \text { wordsearch kemudian masukkan jumlah } \\
\text { baris dan jumlah kolom }\end{array}$ \\
\hline & Listening and speaking & $\begin{array}{l}\text { listen:kata } \\
\text { speak:kata }\end{array}$ \\
\hline
\end{tabular}

Tabel 1 merupakan script dari 8 jenis soal yang dipraktikan oleh peserta pelatihan. Kemudian setelah diberikan pemaparan materi, peserta pelatihan atau guru mencoba untuk membuat LKPD interaktif dengan berbagai jenis soal. Ketika proses peraktik secara langsung, tim pengabdian berkeliling mendampingi guru yang mengalami kesulitan.

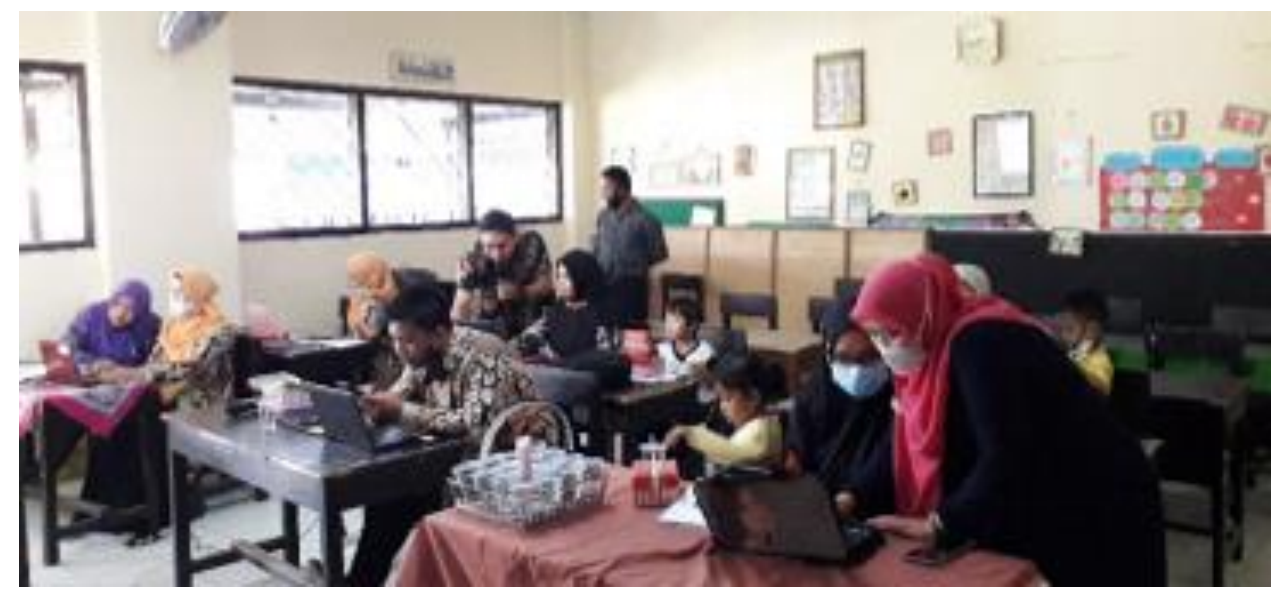

Gambar 3. Proses pendampingan saat praktik membuat LKPD interaktif

Untuk melihat hasil LKPD interaktif yang sudah disusun bisa membuka menu my worksheet. Setelah mengklik menu tersebut maka akan muncul LKPD yang sudah dibuat kemudian pilih LKPD tersebut. Selanjutnya untuk menyebarkan link LKPD interaktif yang sudah disusun cukup mengklik copy/costum link pada kalimat "Link to this worksheet". 


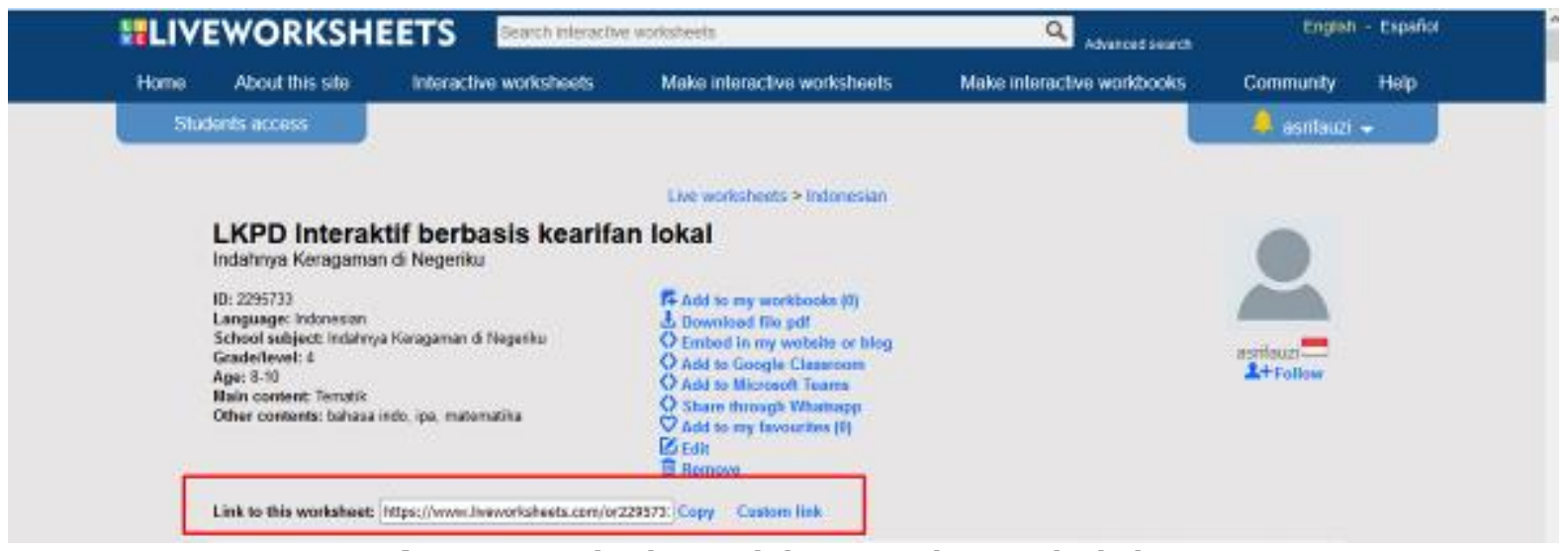

Gambar 4. Tampilan liveworksheets untuk menyalin link LKPD

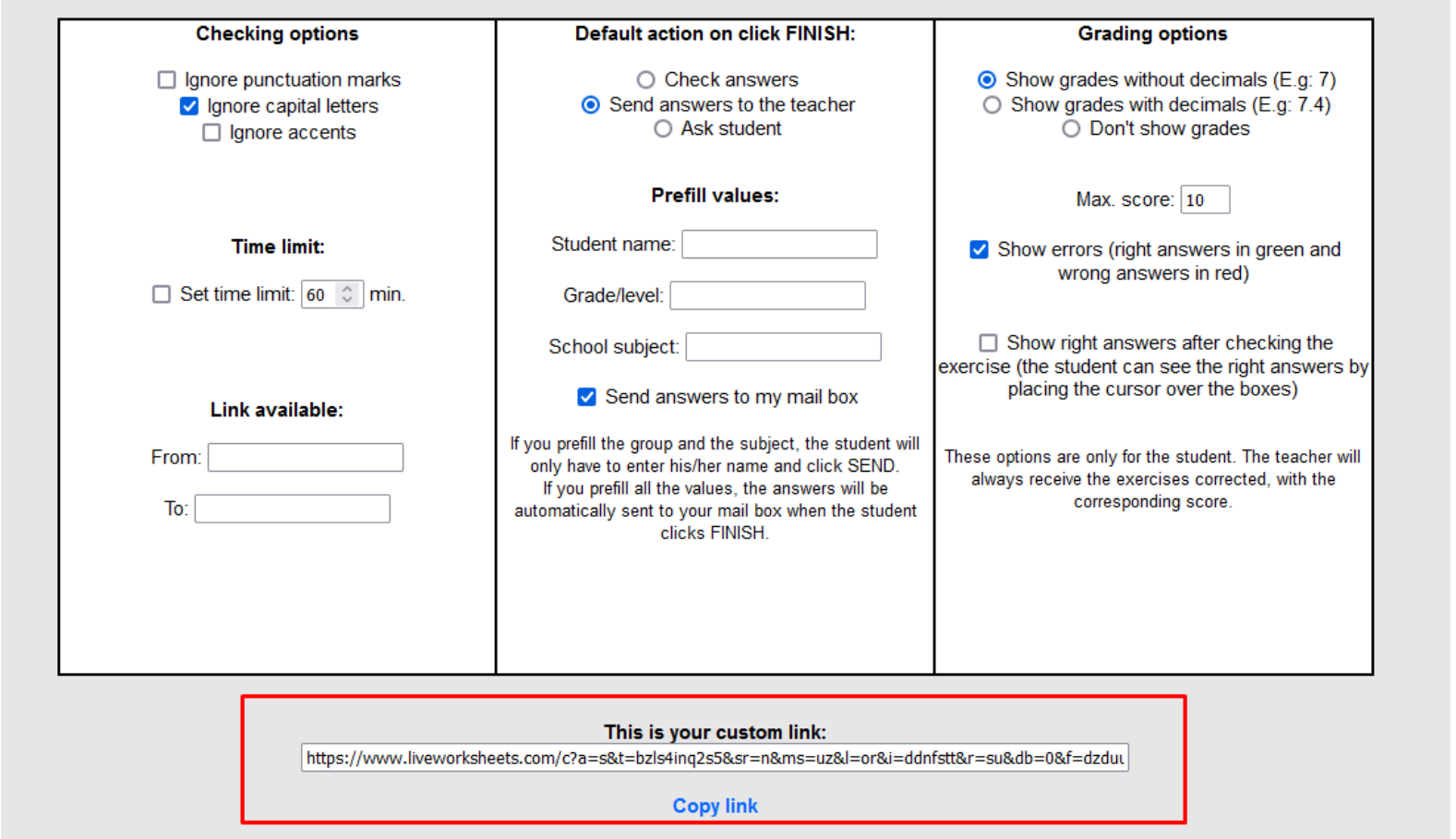

Gambar 5. Tampilan menu costum link

Gambar 4 merupakan tampilan liveworksheets ketika kita sudah mengklik LKPD interaktif yang sudah dibuat. Untuk menyebarkan linknya guru cukup mengklik copy atau costum link. Tampilan setelah mengklik costum link ditunjukan pada gambar 5. Costum link ini untuk mengatur time limit link bisa diakses, maksimal skor, dan lain-lain. Setelah selesai diatur kemudian klik copy link yang berada di bawah kemudian disebar ke grup watshapp kelas. Untuk mencoba LKPD interaktif yang sudah disusun bisa mengklik link berikut: https://www.liveworksheets.com/or2295733su 


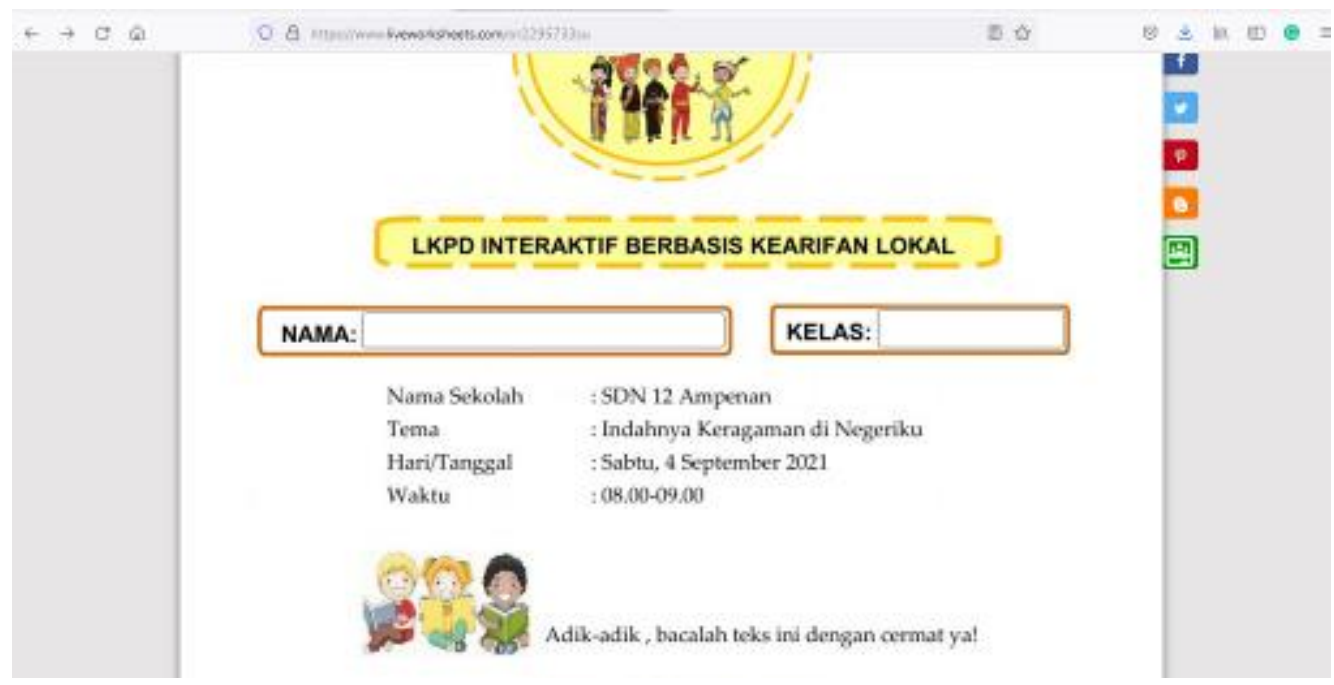

Gambar 6. Tampilan LKPD interaktif

Gambar 6 merupakan tampilan awal LKPD interaktif yang sudah disusun setelah mengklik link yang sudah disebarkan melalui WAG. Untuk mengerjakan soal-soal LKPD, siswa bisa menscrol kebawah.

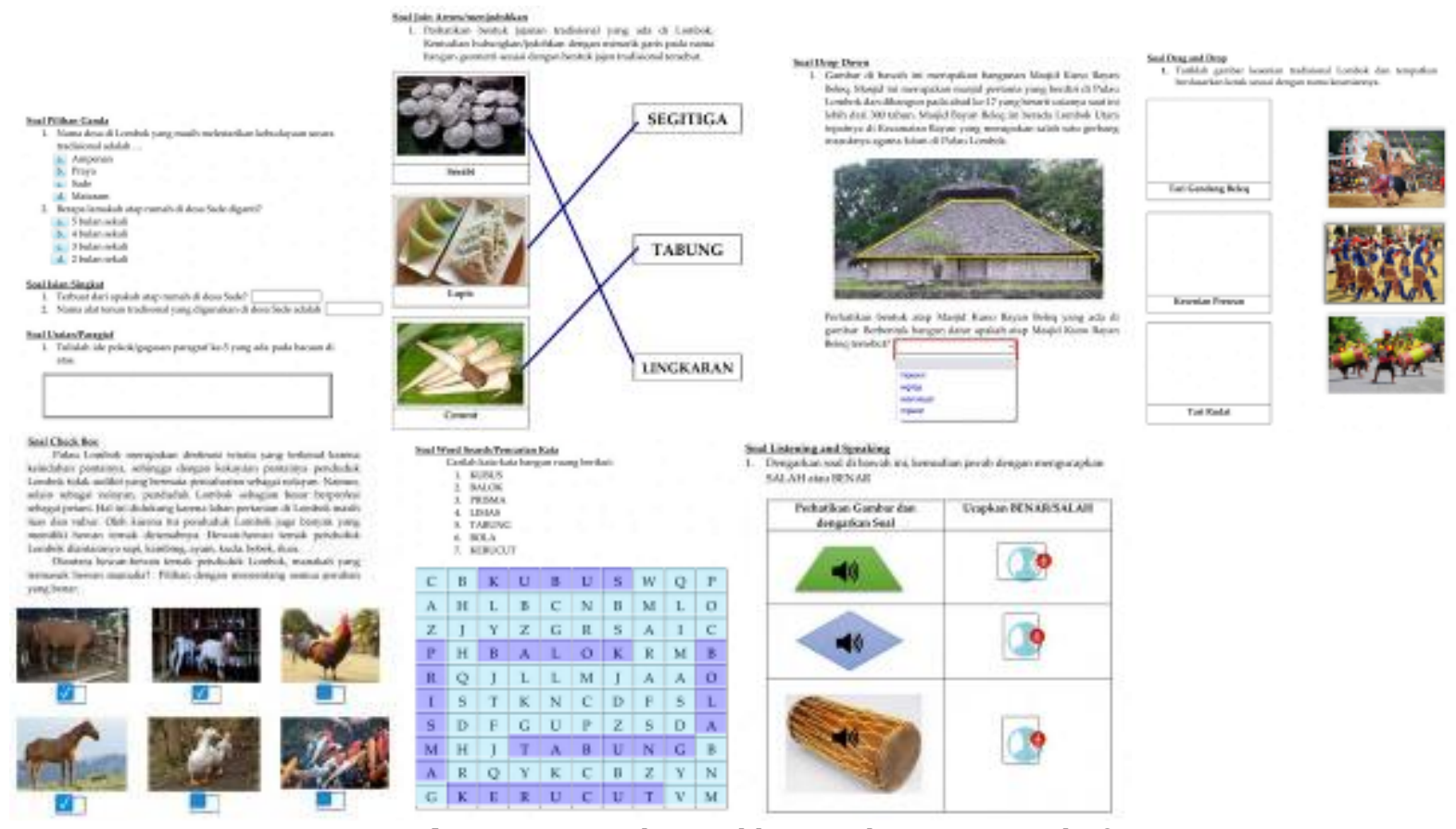

Gambar 7. Jenis soal yang dibuat pada LKPD interaktif

Gambar 7 merupakan berbagai jenis soal yang disusun di dalam LKPD interaktif yaitu soal pilihan ganda, isian singkat, uraian, join arrow, drop down, drag and drop, check box, word search, dan soal listening and speaking. Dengan bertambahnya kemampuan guru untuk membuat berbagai jenis soal di dalam LKPD interaktif, tim pengabdian mengharapkan guru bisa mengembangkan sendiri LKPD sesuai kebutuhannya di dalam proses pembelajaran. Oleh karena itu kegiatan pengabdian ini secara keseluruhan dikatakan berhasil yang ditandai dengan bertambahnya kemampuan guru dalam membuat LKPD interaktif melalui situs liveworksheets.

\section{SIMPULAN DAN TINDAK LANJUT}

Berdasarkan hasil dan pembahasan dari kegiatan pengabdian kepada masyarakat menghasilkan LKPD interaktif yang dibuat melalui situs liveworksheets. LKPD interaktif ini dapat digunakan pada pembelajaran daring yang saat ini dilakukan di seluruh wilayah untuk memudahkan guru dalam proses belajar mengajar sekaligus penilaian. Proses pembelajaran 
menggunakan LKPD interaktif ini akan menambah keaktifan siswa untuk belajar dirumah secara mandiri. Keuntungan menggunakan liveworksheets ini juga, guru lebih mudah dan lebih efisien dalam melakukan penilaian, karena hasil kerja siswa akan tampil pada akun guru.

Tindak lanjut dalam pengabdian kepada masyarakat yaitu proses pendampingan bagi guru yang mengalami kesulitan dalam mengembangkan media pembelajaran terutama pada pembuatan LKPD interaktif. Harapannya dari pelatihan ini, guru mempunyai skill mengembangkan media interaktif yang berbasis teknologi untuk mendukung proses pembelajaran sehingga pembelajaran dapat berjalan sesuai dengan yang diharapkan dan tujuan pembelajaran dapat tercapai.

\section{DAFTAR PUSTAKA}

Alenezi, A. (2020). The role of e-learning materials in enhancing teaching and learning behaviors. International Journal of Information and Education Technology, 10(1), 48-56. https://doi.org/10.18178/ijiet.2020.10.1.1338

Amalia, A. D., \& Lestyanto, L. M. (2021). LKS Berbasis Saintifik Berbantuan Live Worksheets untuk Memahamkan Konsep Matematis pada Aritmetika Sosial. Jurnal Cendekia: Jurnal Pendidikan Matematika, 5(3), 2911-2923.

Andriyani, N., Hanafi, Y., Safitri, I. Y. B., \& Hartini, S. (2020). Penerapan Model Problem Based Learning Berbantuan Lkpd Live Worksheet Untuk Meningkatkan Keaktifan Mental Siswa Pada Pembelajaran Tematik Kelas Va. Prosiding Pendidikan Profesi Guru, September, 122130. http://eprints.uad.ac.id/21216/1/12. Novi Andriyani-PGSD \%28122-130\%29.pdf

Arifin, S., \& Aprisal, A. (2020). Penerapan Model Pembelajaran Kooperatif Tipe Pair Checks Terhadap Kemampuan Pemecahan Masalah Matematika. Jurnal Pendidikan Matematika, 11(1), 89-98. http://ojs.uho.ac.id/index.php/JPM/article/view/11897/pdf

Ermiana, I., Umar, Oktaviyanti, I., Fauzi, A., Hidayati, V. R., \& Setiawan, H. (2020). WORKSHOP PEMBUATAN MEDIA PUZZLE BERBAHAN KARDUS BEKAS BERBASIS TEMATIK DI SD NEGERI 1 TAMANSARI. Jurnal Pendidikan Dan Pengabdian Masyarakat, 3(3), 192-201.

Hazlita, S. (2021). Implementasi Pembelajaran dalam Jaringan dengan Menggunakan Instagram dan Liveworksheets pada Masa Pandemi. JIRA: Jurnal Inovasi Dan Riset Akademik, 2(7), 1142-1150. https://doi.org/10.47387/jira.v2i7.195

Khikmiyah, F. (2021). Implementasi Web Live Worksheet Berbasis Problem Based Learning dalam Pembelajaran. Pedagogy: Jurnal Pendidikan Matematika, 6(1), 1-12.

Lathifah, M. F., Hidayati, B. N., \& Zulandri, Z. (2021). Efektifitas LKPD Elektronik sebagai Media Pembelajaran pada Masa Pandemi Covid-19 untuk Guru di YPI Bidayatul Hidayah Ampenan. Jurnal Pengabdian Magister Pendidikan IPA, 4(2), 25-30. https://doi.org/10.29303/jpmpi.v4i2.668

Muhson, A. (2010). PENGEMBANGAN MEDIA PEMBELAJARAN BERBASIS TEKNOLOGI INFORMASI. Jurnal Pendidikan Akuntansi Indonesia, 8(2), 1-10. https://doi.org/10.21831/jpai.v8i2.949

Muskita, M., Subali, B., \& Djukri. (2020). Effects of worksheets base the levels of inquiry in improving critical and creative thinking. International Journal of Instruction, 13(2), 519532. https://doi.org/10.29333/iji.2020.13236a

Nissa, I. C., Rika, B., Febrilia, A., \& Astutik, F. (2021). Live worksheets matematika: dalam perspektif siswa menurut model motivasi ARCS. Seminar Nasional Matematika Dan Pendidikan Matematika (6th SENATIK), 266-273.

Prastika, Y., \& Masniladevi. (2021). Pengembangan E-LKPD Interaktif Segi Banyak Beraturan 
Dan Tidak Beraturan Berbasis Liveworksheets Terhadap Hasil Belajar Peserta Didik Kelas IV Sekolah Dasar. Journal of Basic Education Studies, 4(1), 2601-2614.

Ratnawati, T. M. (2021). Upaya Meningkatkan Prestasi Belajar pada Pembelajaran Daring Instalasi Motor Listrik Menggunakan Lembar Kerja Peserta Didik (LKPD) Interaktif. JIRA: Jurnal Inovasi Dan Riset Akademik, 2(6), 839-848. https://doi.org/10.47387/jira.v2i6.166

Rhosyida, N., Muanifah, M. T., Trisniawati, \& Hidayat, R. A. (2021). Mengoptimalkan Penilaian Dengan Liveworksheet Pada Flipped Classroom Di Sd. Jurnal Taman Cendekia, 05(01), 568-578. https://jurnal.ustjogja.ac.id/index.php/tamancendekia/article/view/9749

Ryabchikova, V. G., Rubleva, O. S., Sergeeva, N. A., \& Yakovleva, N. A. (2020). Using interactive worksheets when teaching foreign languages by the "flipped class" technology. Perspektivy Nauki i Obrazovania - Perspectives of Science and Education, 45(3), 195-206. https://doi.org/10.32744/pse.2020.3.15

Sao, S., Mei, A., Ningsih, N., Mei, M. F., Wondo, M. T. S., Seto, S. B., Naja, F. Y., Meke, K. D. P., \& Manda, G. S. (2021). Bimbingan Belajar di Rumah Menggunakan Alat Peraga Blok Pecahan pada Masa Pandemi Covid 19. Mitra Mahajana: Jurnal Pengabdian Masyarakat, 2(2), 193201. https://doi.org/10.37478/mahajana.v2i2.1031

Widiyani, A., \& Pramudiani, P. (2021). Pengembangan Lembar Kerja Peserta Didik (LKPD) Berbasis Software Liveworksheet pada Materi PPKn. DWIJA CENDEKIA: Jurnal Riset Pedagogik, 5(1), 132-141. 